\title{
UNIVERSALIDADE DOS DIREITOS SOCIAIS EM TEMPO DE PANDEMIA
}

\author{
UNIVERSALITY OF SOCIAL RIGHTS IN PANDEMIC CONTEXT
}

\author{
Augusto César Leite de Carvalho ${ }^{1}$ \\ João Vítor Barros de Carvalho²
}

\begin{abstract}
Resumo: Este ensaio trata da relevância de o discurso jurídico associar a categorização dos direitos humanos como direitos subjetivos à possibilidade de todos os direitos promocionais, com ênfase para os direitos sociais e para aqueles que remetem ao desenvolvimento humano sustentável, serem exigíveis como políticas públicas que pressupõem, na norma jurídica, mais que um conteúdo meramente programático.
\end{abstract}

Palavras-chave: direitos humanos; direitos sociais; universalidade; igualdade; indivisibilidade.

\begin{abstract}
This essay discusses the importance of associating the definition of human rights as subjective rights and the justiciability of those rights of a promotional nature, with special emphasis on social rights and those related to sustainable development. As a result, those rights become translated into public policies which presuppose, in law, more than a mere programmatic content.
\end{abstract}

Keywords: human rights; social rights; universality; equality; indivisibility.

\section{Escorço histórico sobre a resistência à universalização dos direitos sociais}

A civilização, de leste a oeste, despertou ao final da Segunda Guerra Mundial para a urgência de uma rede internacional de proteção a direitos humanos que alcançasse a todos os povos e nações (Malheiro, 2016). A Carta das Nações Unidas não bastava, pois a paz ali celebrada não teria eficácia prospectiva se um catálogo de direitos não sobreviesse, obrigando a todos os Estados quanto à observância, desde então e para sempre, de valores essenciais à humanidade.

Sobreveio a Declaração Universal de Direitos Humanos (DUDH), em 1948, e nela se

\footnotetext{
${ }^{1}$ Ministro do Tribunal Superior do Trabalho. Mestre em Direito e Desenvolvimento pela Universidade Federal do Ceará, Doutor em Direito das Relações Sociais pela Universidad de Castilla la Mancha, com revalidação no Brasil pela Universidade Federal de Pernambuco, e Pós-doutor em Direitos Humanos pela Universidad de Salamanca. Autor dos livros "Garantia de Indenidade no Brasil", Direito do Trabalho: curso e discurso" " "Princípios de Direito do Trabalho Sob a Perspectiva dos Direitos Humanos", todos pela Editora LTr. É professor de graduação e mestrado no Curso de Direito do IESB - Instituto de Ensino Superior de Brasília e de pós-doutorado em Direitos Humanos na Universidad de Salamanca.

${ }^{2}$ Advogado. Especialista em Direito Digital.
} 
adicionou, a partir da máxima iluminista de que todos os homens nascem iguais em direitos, o arremate, em verdade o pressuposto, de que todos são iguais em dignidade. Liberdades civis e políticas se uniram, em tal proclamação, a direitos econômicos, sociais e culturais que haveriam de ser normalizados, ou simplesmente respeitados como costumes oponíveis em escala planetária. A força normativa ou vinculante dos preceitos contidos na DUDH fora questionada, porém, desde o seu surgimento (Mazzuoli, 2020).

Ainda que não houvesse certeza quanto àquela Declaração de 1948 revestir-se da força normativa dos tratados, fato é que, em meio aos primeiros debates, o compromisso moral de assegurar autodeterminação dos povos e direitos de liberdade causou reação de estados imperialistas, impedindo, na prática, que a política colonialista da Inglaterra ou a política expansionista da União Soviética se coadunassem com a inclusão dos direitos humanos na Carta das Nações Unidas, antes mesmo de se cogitar uma Declaração Universal (Hunt, 2007). Também os Estados Unidos da América resistiram, na mesma ocasião, à pretensão chinesa de que ali se consagrasse a igualdade entre as raças (Hunt, 2007). Superados tais impasses, sobreveio em 1948 a DUDH, sendo ela aprovada por quarenta e oito estados, havendo a abstenção de repúblicas soviéticas e árabes, mas nenhuma recusa à sua aprovação.

$\mathrm{Na}$ Assembleia Geral da ONU de 1968, deliberou-se que a DUDH seria mais que uma compilação dos costumes de direito internacional, pois teria a força normativa do direito compilado em tratados de direitos humanos. Quase simultaneamente, as Nações Unidas envidavam esforços para converterem em tratado, por definitivo, todo o conjunto de direitos que a Declaração proclamava como universais.

Surgiram, nesse toar e em 1966, tratados gerais de direitos humanos com a tarefa de identificar quais os direitos de liberdade, econômicos, sociais e culturais que se imporiam como direitos universais. Mas a proposta de um tratado único malogrou. Foram dois os tratados - o Pacto Internacional sobre Direitos Civis e Políticos e o Pacto Internacional sobre Direitos Econômicos, Sociais e Culturais - porque as duas correntes ideológicas hegemônicas, representadas pelos países do ocidente predominantemente liberal e pelos países do leste socialista, dissentiram quanto à conveniência de converterem em norma jurídica os direitos sociais e os de liberdade, respectivamente (Trindade, 2012).

Em rigor, contra a normatização de direitos sociais havia uma resistência de ordem prática. Como a implementação desses direitos significava um ônus significativo para os estados-partes, pois a universalidade dos serviços de saúde e de educação exigiam, ilustrativamente, recursos econômicos que os países possuíam em proporções diferentes, temia-se que se submetesse a órgãos internacionais o monitoramento desses serviços em grau de exigência que alguns países não conseguiriam suportar (Mazzuoli, 2020).

No âmbito das Américas, a posição refratária dos Estados Unidos à incorporação de direitos econômicos, sociais e culturais fora tal que a Convenção Americana de Direitos Humanos foi 
aprovada, em 1969, com um dispositivo solitário acerca do tema, o art. 26. Nele, previu-se que tais direitos teriam o caráter da progressividade, sem explicitar-se de que direitos, propriamente, estava-se a cuidar.

Somente em 1988 sobreveio o protocolo adicional, o Protocolo de São Salvador, enumerando os direitos econômicos, sociais e culturais que estariam, dali por diante e em todo o território americano, consagrados como direitos humanos. Algo semelhante se deu em solo europeu, dado que também a Convenção Europeia de Direitos Humanos (1950) se ressentia de outros direitos que não os de liberdade, sobrevindo em 1966 a Carta Social Europeia que prescreveria outras dimensões de direitos humanos. Apenas a Carta Africana de Direitos Humanos e dos Povos abrangeu, desde o início, os direitos humanos econômicos, sociais, culturais e ambientais, em 1981 (Piovesan, 2015).

\section{A prevalência dos direitos humanos como direitos subjetivos}

Para os países do leste, havia outra razão para a resistência ao modo como os direitos sociais viriam a ser previstos nos tratados da ONU. É que a ONU sempre prestigiou a concepção de todos os direitos humanos segundo a lógica deôntica própria dos direitos de liberdade, qual seja, a de concebê-los como direitos subjetivos, como se nota à leitura do art. 2.3 do Pacto Internacional Sobre Direitos Civis e Políticos.

Art. 2.3. Os Estados Partes do presente Pacto comprometem-se a:

a) Garantir que toda pessoa, cujos direitos e liberdades reconhecidos no presente Pacto tenham sido violados, possa de um recurso efetivo, mesmo que a violência tenha sido perpetra por pessoas que agiam no exercício de funções oficiais;

b) Garantir que toda pessoa que interpuser tal recurso terá seu direito determinado pela competente autoridade judicial, administrativa ou legislativa ou por qualquer outra autoridade competente prevista no ordenamento jurídico do Estado em questão; e a desenvolver as possibilidades de recurso judicial;

c) Garantir o cumprimento, pelas autoridades competentes, de qualquer decisão que julgar procedente tal recurso.

De modo diferente, a Constituição Russa de 1918 não continha um só dispositivo que tratasse os direitos humanos como garantias individuais (Trindade, 2012). Talvez porque a inspiração marxista parecesse incompatível com o sentido de liberdade endereçado pela filosofia iluminista à preeminência do sujeito de direitos, talvez em razão da firme compreensão de não se poder reivindicar como seu um direito que a todos haveria de igualmente pertencer, o certo é que a Revolução Russa não consentiu a existência de direitos humanos como direitos subjetivos ou individuais.

Por razões que não cabem ser aqui destrinçadas, é fato que a ideologia comunista sucumbiu implacavelmente a partir da década de 1980, levando para o mesmo patíbulo o ideário que correspondia a seu modelo de sociedade igualitária. Sem embargo, a ideia de igualdade não deve 
ser apropriada, em uma de suas vertentes mais auspiciosas, por questões geopolíticas que exerceram sobre ela inicial influência.

Longe estamos de sustentar que a compreensão dos direitos humanos como direitos subjetivos deva ser abandonada. A liberdade individual de ir e vir, pensar e expressar-se, trabalhar ou recusar trabalho, associar-se, reunir-se e ter preservados os espaços privados não pode ser subtraída do catálogo do Direito Internacional dos Direitos Humanos, ou da rede de proteção a direitos humanos internalizados, os direitos fundamentais. É indiscutível a relevância dos direitos humanos e fundamentais como direitos subjetivos, como anotam Abramovich e Courtis (2004, p. 37):

\footnotetext{
"Ainda que um Estado cumpra habitualmente o dever de satisfazer determinadas necessidades ou interesses tutelados por um direito social (por exemplo, se desenvolve um amplo programa de provisão de alimentos à população ameaçada pela fome), nenhum observador poderia afirmar que os beneficiados pela conduta estatal gozam desse direito (por exemplo, do direito a uma alimentação adequada e a estar protegido contra a fome - art. 11.1 e 11.2 do PIDESC) como direito subjetivo enquanto não verificar se a população se encontra realmente em condições de demandar judicialmente a prestação do Estado ante um eventual descumprimento. O que qualifica a existência de um direito social como direito pleno não é simplesmente a conduta cumprida pelo Estado, senão a existência de algum poder jurídico, para agir, do titular do direito em caso de descumprimento da obrigação devida".
}

Há importância, porém, de retomar-se, paralelamente, a trilha evolucional dos direitos humanos como direitos de comunhão ou integração, ou seja, direitos tão distintos "do direito de coordenação (ordem de direito individual) quanto do direito de subordinação, somente reconhecidos pelos sistemas do individualismo jurídico e do universalismo unilateral" (Gurvitch, 2005, p. 8).

A ideia de direitos sociais positivados mediante a cooperação dos próprios atores sociais e a serem usufruídos igualmente, sem distinção em favor dos que os reclamem individualmente, aproxima-se da utopia de igualdade material, realiza-se em extensão que transcende a dos processos contenciosos e deve por isso ser investigada, formulada, normalizada.

De toda sorte, conspira em favor desse descolamento da dimensão individual a compreensão, que já se tem, de os direitos humanos não se adequarem, à perfeição, à vetusta lógica jurídica segundo a qual todo direito deve corresponder à obrigação ou ao dever de alguém cumpri-lo, nos moldes da "obrigação perfeita" a que se referia Kant em sua "Crítica à Razão Prática”. Ao cuidar do tema, Amartya Sen (2010) lembra que o próprio Kant rejeitava a ideia de que essa fosse uma característica necessária a todos os direitos.

Ao transigir quanto a existência de "obrigações imperfeitas", Sen aduz com propriedade: "Evidentemente pode ocorrer, que, assim formulados, os direitos acabem às vezes por não se cumprir. Mas sem dúvida somos capazes de distinguir um direito que uma pessoa tem e que não se cumpriu e um direito que uma pessoa não tem".

Em síntese, o intento de visar à dignidade do ser humano em abstrato, embora sem abandono da dimensão individual, reclama a construção de novos sentidos para a igualdade e a 
universalidade que consubstanciam os direitos humanos, com relevo para os direitos econômicos, sociais, culturais e ambientais.

\section{Direitos sociais e ambientais reclamam políticas públicas universais}

A pandemia do Covid-19 é contingência que, a esse propósito, convida à reflexão. A individualidade do direito à saúde durante a pandemia, coubesse a hipótese de autorizar-se tratamento diverso para ricos e pobres, patrões e empregados, seria idealmente uma acintosa afronta ao caráter fundamental desse e de outros direitos sociais, ou à máxima segundo a qual todos nascemos iguais em dignidade (art. $1^{\circ}$ da DUDH de 1948). São direitos que devem realizarse, antes que o mais, no plano transindividual.

E então há um refinamento semântico da concepção tradicional do que viria a ser um direito universal. A Teoria Geral dos Direitos Humanos tem sustentado que direitos universais são aqueles que assim se apresentam no plano pessoal, temporal e cultural (Ramos, 2013). Vale dizer: são direitos que têm a todas e a cada pessoa como titulares (dimensão pessoal), porque são direitos inatos e inerentes à evolução humana (dimensão temporal), sem distinção pelo fato de esses entes humanos pertencerem a culturas diferentes (dimensão cultural).

Não se afirma, portanto, que, por serem universais, os direitos sociais devem ser garantidos a todas as pessoas na mesma conta. A universalidade da qual se cogita é concebida em abstrato para ser exercida em concreto, ou seja, concebe-se-a a partir do todo mas para a fruição idiossincrática do particular.

É possível, entretanto, divisar tais direitos sob outra perspectiva. Diversamente do que sucede aos direitos de liberdade, que variam em intensidade na proporção inversa da vulnerabilidade social a que se submetem os seus titulares, os direitos econômicos, sociais, culturais e ambientais não se realizam preponderantemente a partir da realidade de cada sujeito em particular.

As diferenças de gênero, etnia, religião - tão relevantes para definir a proporção assegurada às liberdades civis - não importam com igual rigor quando se está em jogo o direito promocional, ou à prestação de serviços de saúde, educação, moradia, assistência e previdência social, transporte e lazer. Há um patamar mínimo a ser garantido como um direito imanente à humanidade.

A linguagem jurídica opera em auxílio. O Pacto Sobre Direitos Econômicos, Sociais e Culturais (PIDESC), ou mesmo o seu similar para as Américas, o Protocolo de São Salvador, embora contenham dispositivos que garantem direitos individuais - o art. $7^{\circ}$ de ambos os tratados prevê o direito a salário mínimo, a jornada máxima, a férias e a isonomia salarial para trabalho de igual valor, ou seja, direitos sociais que se exercem na dimensão subjetiva em vínculos jurídicos 
assimétricos -, os dois tratados contêm dispositivos outros que reclamam a igualdade de todos, a um só tempo, como ponto de partida e como escopo jurídico.

Cabe exemplificar. Não obstante os avanços na direção da pronta justiciabilidade dos direitos econômicos, sociais e culturais ${ }^{3}$, é certo que quando o PIDESC contempla a proteção integral à família, à maternidade e à infância (artigos 10 e 11), o direito ao "mais elevado nível possível de saúde física e mental" (art. 12) ou o direito à educação "de toda pessoa" que visa "ao pleno desenvolvimento da personalidade humana e do sentido de sua dignidade e (a) fortalecer o respeito pelos direitos humanos e liberdades fundamentais" (art. 13), está a assegurar direitos que logram validez social indiscutivelmente maior quando compreendidos como direitos a serem garantidos à universalidade, a toda a humanidade.

E quando os direitos humanos avançam, nessa senda dos direitos promocionais, para gradualmente incorporar o direito ao meio ambiente sustentável - sobretudo a partir da Declaração de Estocolmo de 1972 -, a primazia da subjetividade aparece mitigada, como se pode inferir do art. 24 da Carta Africana dos Direitos Humanos e dos Povos: "Todos os povos têm direito a um meio ambiente geral satisfatório, propício ao seu desenvolvimento”. Não há menção a todas as pessoas, mas a todos os povos.

E se esses mesmos direitos relacionados à sustentabilidade se refletem nos textos das constituições nacionais, mantém-se a remissão ao holístico, ao universal, como se pode perceber à leitura do art. 225 da Constituição brasileira: "Todos têm direito ao meio ambiente ecologicamente equilibrado, bem de uso comum do povo e essencial à sadia qualidade de vida, impondo-se ao Poder Público e à coletividade o dever de defendê-lo e preservá- lo para as presentes e futuras gerações".

\section{Objetividade com efetividade dos direitos sociais e ambientais}

A ênfase na objetividade do direito promocional não compromete sua efetividade. A

\footnotetext{
${ }^{3}$ Anote-se, ilustrativamente, o que decidiu o Comitê de Direitos Econômicos, Sociais e Culturais da ONU na Observação Geral n. 3.5 do Comitê de Direitos Econômicos Sociais e Culturais: "Entre las medidas que cabría considerar apropiadas, además de las legislativas, está la de ofrecer recursos judiciales en lo que respecta a derechos que, de acuerdo con el sistema jurídico nacional*, puedan considerarse justiciables. El Comité observa, por ejemplo, que el disfrute de los derechos reconocidos, sin discriminación, se fomentará a menudo de manera apropiada, en parte mediante la provisión de recursos judiciales y otros recursos efectivos. De hecho, los Estados Partes que son asimismo Partes en el Pacto Internacional de Derechos Civiles y Políticos están ya obligados (en virtud de los artículos 2 (párrs. 1 y 3), 3 y 26 de este Pacto) a garantizar que toda persona cuyos derechos o libertades (inclusive el derecho a la igualdad y a la no discriminación) reconocidos en el presente Pacto hayan sido violados, "podrá interponer un recurso efectivo" (apartado a) del párrafo 3 del artículo 2). Además, existen en el Pacto Internacional de Derechos Económicos, Sociales y Culturales varias otras disposiciones, entre ellas las de los artículos 3, 7 (inciso i) del apartado a)), 8, 10 (párr. 3), 13 (apartado a) del párrafo 2 y párrafos 3 y 4) y 15 (párr. 3), que cabría considerar de aplicación inmediata por parte de los órganos judiciales y de otra índole en numerosos sistemas legales nacionales. Parecería difícilmente sostenible sugerir que las disposiciones indicadas son
} 
atribuição de direitos que exigem mais que a abstenção do poder político ou social, mas sim a promoção de meios ou utilidades imprescindíveis à existência digna, não raro é interpretada como a compor uma pauta meramente programática, sem a pronta efetividade de que somente as liberdades civis e políticas se revestiriam. Esse modo de pensar comporta, porém, reservas tanto ontológicas quanto deontológicas.

É que a ontologia dos direitos de liberdade não é a de direitos que exijam apenas a abstenção do Estado ou de organizações sociais investidas de poder. Conforme ensinam Abramovich e Courtis, também as liberdades civis e políticas demandam atuação positiva do Estado, quando menos em questões relacionadas à segurança pessoal e à atividade jurisdicional. Em rigor, afirmam:

“[...] a adstrição de um direito ao catálogo de direitos civis e políticos ou ao de direitos econômicos, sociais e culturais tem um valor heurístico, ordenador, classificatório, mas que uma conceituação mais rigorosa baseada no caráter das obrigações que cada direito gera levaria a admitir um continuum de direitos, em que o lugar de cada direito esteja determinado pelo peso simbólico do componente de obrigações positivas ou negativas que o caracterizem" (2004, p. 27).

Por outro lado, a deontologia do juiz, o seu modo de comportar-se ante a cobrança de direitos sociais, não pode traduzir-se em inércia, como se todo encargo recaísse em outros setores do Estado responsáveis pela formulação e execução de políticas públicas voltadas à promoção do bem-estar social. O tema, como se pode notar em seguida, não é pacífico entre os teóricos do direito das gentes e do direito constitucional.

Peces-Barba (2006, p. 72), na Espanha, após concluída a elaboração da Constituição de seu país (para a qual contribuiu como membro da Assembleia Constituinte), admitiu ser cético quanto à pronta exigibilidade dos direitos sociais:

"Ainda que o texto constitucional tenha dado nesse campo passos importantes, encontram-se com proteção inferior os direitos econômicos, sociais e culturais que são somente princípios reitores ou que não se encontram na seção $1^{a}$ do capítulo Il do Título I. Também aqui se põe em relevo o caráter misto do conceito de Direito que se desprende da Constituição, com influência liberal e socialista, porque também a função garantista, própria dos direitos de liberdade, prima sobre a função promocional, própria dos direitos de igualdade [...] "

Esse ceticismo talvez se deva ao grau muito elevado de abstração com que se enumeram os direitos sociais na Constituição da Espanha. Ainda assim, não parece ser essa a corrente doutrinária prevalecente, mesmo quando consideramos cartas constitucionais, como a alemã de 1949, em que os direitos sociais têm abordagem ainda menos analítica. Vale a pena consignar o

\footnotetext{
${ }^{4}$ No original: "Aunque el texto constitucional ha dado en este campo pasos importantes, aún se encuentran en inferioridad de protección los derechos económicos, sociales y culturales que son sólo principios rectores o que no se encuentran en la sección $1^{a}$ del capítulo II del Título I. También aquí se pone de relieve el carácter mixto del concepto del Derecho que se desprende de la Constitución, con influencia liberal y socialista, porque todavía la función garantizadora, propia de los derechos de libertad, prima sobre la función promocional, propia de los derechos de igualdad [...]".
} 
que, referindo-se à Constituição dos germanos, sustentou Alexy:

"Como tem revelado a jurisprudência do Tribunal Constitucional Federal (alemão), de modo algum um tribunal constitucional é impotente frente a um legislador inoperante. $\mathrm{O}$ espectro de suas possibilidades processuais-constitucionais se estende, desde a mera constatação de uma violação da Constituição, através da fixação de um prazo dentro do qual deve levar-se a cabo uma legislação acorde com a Constituição, até a formulação judicial direta do ordenado pela Constituição" (apud Abramovich e Courtis, 2004, p. 47).

E Claus-Wilhelm Canaris (2016, p. 34) nos conta que o Tribunal Constitucional Alemão, ao interpretar o alcance da "liberdade de escolha da profissão" consagrada no art. 12 da Lei Fundamental de Bonn, daí extraiu que a norma infraconstitucional (Lei de Proteção Contra os Despedimentos) estavå nele alicerçada ao proteger o trabalhador contra a perda (não motivada) de seu posto de trabalho.

Aparentemente a contrariar a premonição de Peces-Barba, o Tribunal Constitucional da Espanha, na paradigmática sentença STC 22/1981, também afirmou que o direito fundamental ao trabalho importava o direito a trabalho digno e, portanto, não consentia o despedimento não motivado de trabalhadores contratados por tempo indeterminado. Ferrajoli (2014) aponta, no mesmo sentido, as sentenças 47/1976 e 189/1980 do Tribunal Constitucional da Itália.

Em âmbito internacional, a Observação Geral n. 18 do Comitê de Direitos Econômicos, Sociais e Culturais também extraiu do direito ao trabalho a conclusão de estar ali consagrado o direito ao trabalho digno e, portanto, insuscetível de desfazimento sem a devida motivação. Ao decidir o caso Lagos del Campo versus Peru, a Corte Interamericana de Direitos Humanos decidiu, por igual, que o direito fundamental ao trabalho era o que bastava para assegurar ao senhor Alfredo Lagos del Campo o direito de retornar ao emprego do qual fora retirado sem justa motivação.

Em nenhum desses casos, o preceito jurídico, ao veicular o direito humano e fundamental ao trabalho, referiu-se ao direito de o empregado não ser dispensado sem que o motivo da despedida seja a ele informado. Tudo a demonstrar que o elevado grau de abstração dos dispositivos convencionais e constitucionais que asseguram o direito ao trabalho não tem impedido que nesse direito social se vislumbre, para além da letra da lei, o direito a trabalho digno e, nessa medida, a proteção contra a dissolução não motivada do contrato de emprego.

Logo, é possível que superemos algum questionamento acerca da efetividade dos direitos sociais, como categoria dos direitos humanos, para situarmos enfim o problema - que estamos a enfrentar - em outros escaninhos teóricos, mais claramente aqueles relacionados a institutos

\footnotetext{
${ }^{5}$ Artigo 12 da Lei Fundamental de Bonn [Liberdade de escolha da profissão] (1) Todos os alemães têm o direito de eleger livremente a sua profissão, o lugar de trabalho e o de aprendizagem. O exercício da profissão pode ser regulamentado por lei ou em virtude de lei. (2) Ninguém poderá ser obrigado a determinado trabalho, salvo no âmbito de uma tradicional e geral prestação de serviços públicos obrigatórios, igual para todos. (3) Trabalhos forçados só são admissíveis no caso de penas privativas de liberdade impostas por sentença judicial.
} 
muito caros aos direitos humanos, os da igualdade material e da universalidade.

A pandemia é paradoxalmente profilática quanto à compreensão de ser a universalidade dos direitos humanos um atributo que deve adjetivar não somente o direito subjetivo - de todas as pessoas de todos os tempos e de todas as culturas - mas também o direito objetivo à saúde (universal), à educação (universal), à previdência (universal), à formação cultural (universal), ao meio ambiente ecologicamente equilibrado.

Essa digressão conceitual nem sempre é de fácil trânsito em relação a alguns direitos sociais. Poderia questionar-se, exempli gratia, como assegurar tal universalidade (a direitos objetivos de índole prestacional ou promocional com igual extensão para todos) quando se trata dos direitos sociais ao trabalho ou à assistência aos desamparados, pois já agora estamos a cuidar de utilidades que necessariamente variariam, em intensidade, a depender do estrato social ou capacidade econômica de quem as reivindique.

Em rigor, a susceptibilidade maior de alguns indivíduos à carência de direitos sociais, nomeadamente dos despossuídos, está potencialmente à vista também quando estamos a cuidar do direito à saúde, à educação e à cultura, pois é fato incontroverso que, na face oposta dessa atribuição de direitos, a melhor condição econômica pode custear o usufruto de quaisquer serviços, inclusive daqueles que o estado do bem-estar social deveria prover sem qualquer distinção. O que diferencia a saúde, a educação e a cultura é que o mínimo exigido em favor dos despossuídos deveria equivaler ao máximo que a riqueza material pudesse granjear. A régua de proteção, para eles, é sempre a mais alta possível.

Trabalho e assistência social são, distintamente, utilidades de que pode prescindir a camada social economicamente privilegiada. Todavia, e enquanto vivermos a experiência de a troca de utilidades se realizar por meio da circulação de dinheiro ou o que o valha, o direito ao trabalho e à assistência social se traduz, antes, no direito à renda indispensável à concretização de todos os demais direitos humanos.

Nesse ponto, caberia inclusive especular a futura sustentabilidade dos sistemas atuais, fundados na lógica capitalista de produção, caso se confirmem os prognósticos de que todo trabalho manual ou material estaria migrando para a automação. É de se questionar: como idealizar a sociedade em que o trabalho, cada vez mais, é substituído por cadeias produtivas de bens e serviços que prescindem da intervenção humana e, portanto, não proporcionam salários que geram consumo e estímulo a todos os setores da economia? Há capitalismo sem consumo proveniente da massa salarial?

A alternativa que se apresenta é a universalização de outro direito que, ante a nova realidade, ganharia a dignidade de direito humano: o da renda básica. O ponto merece especial destaque.

\section{O direito social à renda básica universal}


A ideia tradicional de renda básica universal consiste em um projeto de política pública no qual o Estado garante periodicamente, a todo cidadão, uma quantia capaz de assegurar as suas necessidades pessoais básicas e mantê-lo acima da linha da pobreza. Não é uma ideia nova: ao que consta, foi esboçada no livro Utopia, do intelectual inglês Thomas More, em 1516. Depois disso, foi desenvolvida por diversos pensadores importantes ao longo da história (Insoni, 2020).

Tantos anos depois, a ideia de renda básica universal mostra-se atualmente como uma potencial forma de garantir a manutenção do direito à renda às classes mais pobres, no momento em que dados apontam que a evolução tecnológica resultará na automação de quase todo trabalho manual e material . Mas ela vai muito além: garante a equiparação das classes quanto à liberdade de trabalhar, e, ideálmente, até mesmo o direito ao trabalho em sua essência.

Como antecipado, na perspectiva dos despossuídos, o direito ao trabalho se traduz em direito à renda, indispensável à concretização de todos os demais direitos humanos. No modelo aqui analisado, contudo, a mudança é sintomática: garantido o direito à renda independentemente de trabalho, as classes menos favorecidas tornam-se livres para prescindir dele, ou, melhor ainda, procurar e investir no labor que tem aptidão para promover, mais que o sacrifício ou o enfado, a emancipação existencial de quem trabalha. Nesse último cenário, a especialização é consequência. E, com ela, o trabalho tende a ser provido de sentido e com maior aptidão para gerar realização (direito ao trabalho propriamente).

De forma bem mais lenta do que o avanço da tecnologia e da automação do trabalho, o debate sobre a implementação da política pública tem avançado. Países como Canadá, Reino Unido, Holanda, Finlândia, Itália, Zimbábue e Quênia, por exemplo, já têm testes contundentes sobre o modelo e os resultados são especialmente positivos. Alguns deles são citados em pesquisa acadêmica levada a efeito por Ananda Isoni:

"No experimento de Mincome, conduzido no Canadá entre 1974 e 1978, os resultados revelaram que os adolescentes das famílias participantes do programa completaram um ano a mais de escolaridade. Também foi relatado o decréscimo da taxa de hospitalização para 8,5\%, com quedas expressivas nas admissões por acidentes e lesões e diagnósticos de adoecimento mental. No Zimbábue, as taxas de vacinação de crianças e frequência escolar aumentaram após um ano de transferências em dinheiro. Já na Finlândia, em piloto conduzido de 2017 a 2018, os resultados demonstraram menor incidência de problemas relacionados a saúde, estresse e capacidade de concentração. Em nenhum dos três casos as transferências estavam condicionadas ao atendimento de exigências."

Em março de 2020, já no contexto da pandemia, a medida foi lembrada por Juan Pablo Bohoslavsky, especialista independente da ONU, que recomendou aos governos que considerassem a renda básica universal de emergência em razão do Covid 19. Talvez fosse a

\footnotetext{
${ }^{6}$ De forma concreta, aponta Ananda Isoni, referindo-se a ORGANIZAÇÃO INTERNACIONAL DO TRABALHO, Trabajar para um futuro más prometedor, 2019: “antes de 2030 é preciso criar 344 milhões de empregos; 190 milhões de pessoas estão desempregadas, das quais 64,8 milhões são jovens; 2 bilhões de pessoas baseiam seu sustento na economia informal; 300 milhões de trabalhadores vivem em situação de extrema pobreza (<1,90 dólar/dia)".
} 


\section{O direito social à renda básica universal}

A ideia tradicional de renda básica universal consiste em um projeto de política pública no qual o Estado garante periodicamente, a todo cidadão, uma quantia capaz de assegurar as suas necessidades pessoais básicas e mantê-lo acima da linha da pobreza. Não é uma ideia nova: ao que consta, foi esboçada no livro Utopia, do intelectual inglês Thomas More, em 1516. Depois disso, foi desenvolvida por diversos pensadores importantes ao longo da história (Insoni, 2020).

Tantos anos depois, a ideia de renda básica universal mostra-se atualmente como uma potencial forma de garantir a manutenção do direito à renda às classes mais pobres, no momento em que dados apontam que a evolução tecnológica resultará na automação de quase todo trabalho manual e material ${ }^{6}$. Mas ela vai muito além: garante a equiparação das classes quanto à liberdade de trabalhar, e, idealmente, até mesmo o direito ao trabalho em sua essência.

Como antecipado, na perspectiva dos despossuídos, o direito ao trabalho se traduz em direito à renda, indispensável à concretização de todos os demais direitos humanos. No modelo aqui analisado, contudo, a mudança é sintomática: garantido o direito à renda independentemente de trabalho, as classes menos favorecidas tornam-se livres para prescindir dele, ou, melhor ainda, procurar e investir no labor que tem aptidão para promover, mais que o sacrifício ou o enfado, a emancipação existencial de quem trabalha. Nesse último cenário, a especialização é consequência. E, com ela, o trabalho tende a ser provido de sentido e com maior aptidão para gerar realização (direito ao trabalho propriamente).

De forma bem mais lenta do que o avanço da tecnologia e da automação do trabalho, o debate sobre a implementação da política pública tem avançado. Países como Canadá, Reino Unido, Holanda, Finlândia, Itália, Zimbábue e Quênia, por exemplo, já têm testes contundentes sobre o modelo e os resultados são especialmente positivos. Alguns deles são citados em pesquisa acadêmica levada a efeito por Ananda Isoni:

"No experimento de Mincome, conduzido no Canadá entre 1974 e 1978, os resultados revelaram que os adolescentes das famílias participantes do programa completaram um ano a mais de escolaridade. Também foi relatado o decréscimo da taxa de hospitalização para 8,5\%, com quedas expressivas nas admissões por acidentes e lesões e diagnósticos de adoecimento mental. No Zimbábue, as taxas de vacinação de crianças e frequência escolar aumentaram após um ano de transferências em dinheiro. Já na Finlândia, em piloto conduzido de 2017 a 2018, os resultados demonstraram menor incidência de problemas relacionados a saúde, estresse e capacidade de concentração. Em nenhum dos três casos as transferências estavam condicionadas ao atendimento de exigências."

Em março de 2020, já no contexto da pandemia, a medida foi lembrada por Juan Pablo Bohoslavsky, especialista independente da ONU, que recomendou aos governos que

\footnotetext{
${ }^{6}$ De forma concreta, aponta Ananda Isoni, referindo-se a ORGANIZAÇÃO INTERNACIONAL DO TRABALHO, Trabajar para um futuro más prometedor, 2019: “antes de 2030 é preciso criar 344 milhões de empregos; 190 milhões de pessoas estão desempregadas, das quais 64,8 milhões são jovens; 2 bilhões de pessoas baseiam seu sustento na economia informal; 300 milhões de trabalhadores vivem em situação de extrema pobreza $(<1,90$
} 
oportunidade para o Brasil regulamentar a Lei n ${ }^{\circ}$ 10.835/2004 (que instituiu no país a renda básica universal), mas, apesar de se ter notícia de que o debate avançou no Congresso Nacional, não há qualquer indício de que isso esteja para acontecer.

A propósito, não haveria relevância em se pontuar a universalidade como a característica de um direito igualmente distribuído se tal implicasse a menor efetividade dos direitos econômicos, sociais, culturais e ambientais. Cabe investigar, então, um claro indicador da efetividade, ou pronta exigibilidade, de políticas públicas que veiculem direitos promocionais: a sua justiciabilidade.

\section{A justiciabilidade dos direitos promocionais}

\section{A jurisprudência da Corte Interamericana de Direitos Humanos}

A possibilidade de exigir-se em juízo a dimensão promocional dos direitos humanos, sem que se tenha em vista apenas o indivíduo atingido pela violação, pode ser percebida em precedentes da Corte Interamericana de Direitos Humanos e do Supremo Tribunal Federal.

$\mathrm{Na}$ atuação da Corte Interamericana de Direitos Humanos, o ordinário é que se apreciem direitos, supostamente violados, de pessoas ou grupos predefinidos, normalmente após o filtro de admissibilidade exercido pela Comissão Interamericana. Entretanto, essa delimitação subjetiva não tem impedido que a Corte revele a sua compreensão de que são interdependentes e interrelacionados todos os direitos humanos e, por isso, a solução judicial não deve estar dirigida apenas à harmonização de interesses intersubjetivos, mas deve transcendê-los para promover condições socioeconômicas que revertam o quadro de carência de direitos objetivos identificada como causa remota do ilícito.

O caso Villagran Morales é disso emblemático. Nele se decidiu acerca do sequestro, tortura e assassinato de jovens por policiais, na Guatemala. Seria esperado que a Corte condenasse o Estado da Guatemala por violação do direito à vida, entre outras transgressões à Convenção Americana e a outros tratados. Assim se deu. Entretanto, e superando as expectativas naturais, a Corte pontuou que a vida é direito que não se vulnera apenas quando se a subtrai, mas também quando não se a promove plenamente. Do voto condutor extrai-se:

\footnotetext{
"En esencia, el derecho fundamental a la vida comprende, no sólo el derecho de todo ser humano de no ser privado de la vida arbitrariamente, sino también el derecho a que no se le impida el acceso a las condiciones que le garanticen una existencia digna. Los Estados tienen la obligación de garantizar la creación de las condiciones que se requieran para que no se produzcan violaciones de ese derecho básico y, en particular, el deber de impedir que sus agentes atenten contra él."
}

O então presidente da Corte Interamericana, ao votar, endossou a premissa de serem indivisíveis os direitos humanos de todas as dimensões, ao rematar:

"En el presente caso Villagrán Morales versus Guatemala (Fondo), atinente a la muerte de niños por agentes policiales del Estado, hay la circunstancia agravante de que la vida de los niños ya carecía de cualquier sentido; es decir, los niños victimados ya se 
encontraban privados de crear y desarrollar un proyecto de vida y aun de procurar un sentido para su propia existencia."

"El deber del Estado de tomar medidas positivas se acentúa precisamente en relación con la protección de la vida de personas vulnerables e indefensas, en situación de riesgo, como son los niños en la calle. La privación arbitraria de la vida no se limita, pues, al ilícito del homicidio; se extiende igualmente a la privación del derecho de vivir con dignidad. Esta visión conceptualiza el derecho a la vida como perteneciente, al mismo tiempo, al dominio de los derechos civiles y políticos, así como al de los derechos económicos, sociales y culturales, ilustrando así la interrelación e indivisibilidad de todos los derechos humanos."

Com coerência, a Corte Interamericana de Direitos Humanos condenou o Estado da Guatemala não somente a indenizar os familiares dos jovens mortos, mas também a modificar suas leis internas e a construir uma escola, pois o valor da vida é também, arrematamos nós, uma construção cultural.

\section{A jurisprudência do Supremo Tribunal Federal}

No âmbito interno, vemos como pioneiros, dentre as cortes constitucionais, alguns precedentes do Supremo Tribunal Federal que impõem, mais que a realização de direitos subjetivos, o desenvolvimento de políticas públicas a que estaria obrigado o Estado brasileiro. É disso antológico o comando que se extrai do julgamento do AGRRE 271286/RS, Rel. Min. Celso de Mello (DJU 24/11/2000), assim ementado:

PACIENTE COM HIV/AIDS - PESSOA DESTITUÍDA DE RECURSOS FINANCEIROS - DIREITO À VIDA E À SAÚDE - FORNECIMENTO GRATUITO DE MEDICAMENTOS - DEVER CONSTITUCIONAL DO PODER PÚBLICO (CF, ARTS. $5^{\circ}$, CAPUT, E 196) - PRECEDENTES (STF) - RECURSO DE AGRAVO IMPROVIDO. O DIREITO À SAÚDE REPRESENTA CONSEQÜÊNCIA CONSTITUCIONAL INDISSOCIÁVEL DO DIREITO À VIDA. - O direito público subjetivo à saúde representa prerrogativa jurídica indisponível assegurada à generalidade das pessoas pela própria Constituição da República (art. 196). Traduz bem jurídico constitucionalmente tutelado, por cuja integridade deve velar, de maneira responsável, o Poder Público, a quem incumbe formular - e implementar - políticas sociais e econômicas idôneas que visem a garantir, aos cidadãos, inclusive àqueles portadores do vírus HIV, o acesso universal e igualitário à assistência farmacêutica e médico-hospitalar. - O direito à saúde - além de qualificar-se como direito fundamental que assiste a todas as pessoas - representa consequência constitucional indissociável do direito à vida. O Poder Público, qualquer que seja a esfera institucional de sua atuação no plano da organização federativa brasileira, não pode mostrar-se indiferente ao problema da saúde da população, sob pena de incidir, ainda que por censurável omissão, em grave comportamento inconstitucional. A INTERPRETAÇÃO DA NORMA PROGRAMÁTICA NÃO PODE TRANSFORMÁ-LA EM PROMESSA CONSTITUCIONAL INCONSEQÜENTE. O caráter programático da regra inscrita no art. 196 da Carta Política - que tem por destinatário todos os entes públicos que compõem, no plano institucional, a organização federativa do Estado brasileiro - não pode converter-se em promessa constitucional inconsequente, sob pena de o Poder Público, fraudando justas expectativas nele depositadas pela coletividade, substituir, de maneira ilegítima, o cumprimento do seu impostergável dever por um gesto irresponsável de infidelidade governamental ao que determina a própria Lei Fundamental do Estado" [...].

Em tempo ainda mais recente, na mesma linha, o Min. Luís Roberto Barroso determinou ao 
Poder Executivo a criação de barreiras sanitárias que impeçam o ingresso de terceiros em territórios indígenas enquanto durar a pandemia de COVID-19. (ADPF 709/DF, Rel. Min. Luís Roberto Barroso, DJU 09/07/2020). Em decisão cautelar posteriormente referendada pela maioria dos ministros no Plenário, destacou-se:

"No que respeita aos povos indígenas em isolamento ou de contato recente, a opção pelo não contato decorre de seu direito à autodeterminação e constitui uma forma de preservar a sua identidade cultural e as suas próprias organizações, usos, costumes e tradições [...]. Nessa medida, o ingresso de qualquer membro exógeno à comunidade, sem a sua autorização, constitui um ilícito. Tais povos têm direito ao isolamento e o Estado tem o dever de assegurá-lo [...]. Mas não é só. Na atual situação, em que há uma pandemia em curso, os povos em isolamento e de contato recente são os mais expostos ao risco de contágio e de extinção. Isso ocorre em razão das condições de vulnerabilidade imunológica e sociocultural já narradas. Por essa razão e de acordo com diretrizes internacionais da ONU e da Comissão IDH, a medida protetiva mais eficaz a ser tomada em favor de tais povos é assegurar-lhes o isolamento da sociedade envolvente, por meio de barreiras ou cordões sanitários que impeçam - inclusive com o uso da força, se necessário - o acesso de estranhos às suas terras."

Em suma, o direito atribuído a cada ser humano de exigir o cumprimento de normas que veiculam direitos humanos e fundamentais é uma conquista da pós-modernidade. Mas sem dúvida é preciso impor aos poderes constituídos - na esfera estatal ou privada - a promoção de direitos econômicos, sociais, culturais e ambientais que se realizam de modo igualmente distributivo, sendo essa forma transcendente ou transindividual de concretização uma característica imanente a esses direitos. E há avanço, na experiência jurídica, para que se acredite na justiciabilidade dos direitos promocionais, mesmo quando vistos em tal perspectiva.

\section{À guisa de conclusão}

Os direitos sociais demoraram a ser positivados em normas universalmente vinculantes. A demora se deu principalmente por duas razões: enquanto os países do ocidente predominantemente liberal receavam que a universalidade dos direitos sociais gerasse para si próprios despesas econômicas, os do leste socialista não queriam admitir a implementação de garantias individuais. Superado esse cenário e reconhecida a oponibilidade universal, a discussão que se impõe diz respeito à efetividade desses direitos em perspectiva transindividual.

Em linha de premissa, é importante registrar que, sem prejuízo do caráter subjetivo inerente e fundamental às normas de direitos humanos -, neste ensaio se pretende discutir a efetividade do caráter objetivo dessas normas universais de direitos sociais. Em outras palavras, propõe-se discutir em que medida essas disposições impõem ao Estado o dever de estabelecer políticas púbicas que garantam, em igual extensão, direitos essenciais a toda a humanidade.

O contexto de pandemia da COVID-19, como se pode prever, torna a discussão ainda mais relevante, pois afinal viabiliza que se enxerguem as carências aflitivas de direitos promocionais, com ênfase para o direito universal à saúde. Todavia, tão ou mais relevante é que os direitos econômicos, sociais, culturais e ambientais sejam exigíveis em extensão tal que permita a todos o 
mesmo ponto de partida para o exercício, em plenitude, de todas as liberdades.

Efetivamente, a ênfase na objetividade do direito promocional não compromete sua efetividade. Sem exagero, é possível dizer que o dever de garantir a eficácia dessas normas é oponível aos Poderes Legislativo e Executivo - exigindo plena atuação positiva - e, com alguma ressalva doutrinária relevante, também ao Poder Judiciário. Quanto a esse último, aliás, julgados paradigmas da Corte Interamericana de Direitos Humanos e do Supremo Tribunal Federal demonstram que ambas as Cortes já desempenham esse papel, garantindo esses direitos a todos em igual extensão.

\section{Referências}

ABRAMOVICH, Victor. COURTIS, Christian. Los Derechos Sociales Como Derechos Exigibles. Tradução livre. Madrid: Trotta, 2004.

CANARIS, Claus-Wilhelm. Direitos fundamentais e direito privado. Tradução de Ingo Wolfgang Sarlet e Paulo Mota Pinto. Coimbra: Almedina, 2016.

FERRAJOLI, Luigi. La Democracia a través de los derechos: el constitucionalismo garantista como modelo teórico y como proyecto político. Tradução para o espanhol de Perfecto Andrés Ibáñez. Versão eletrônica. Madrid: Editorial Trotta, 2014, paginação irregular.

GURVITCH, Georges. La idea del derecho social (1932). Tradução de José Luis Monereo Pérez e Antonio Marquez Prieto. Granada: Editorial Comares, 2005.

HUNT, Lyan. A invenção dos direitos humanos: uma história. São Paulo: Companhia das Letras, 2007. Livro eletrônico, paginação irregular.

ISONI, Ananda T. Renda Básica Universal: um debate necessário. In: Quarentena: reflexoes sobre a pandemia e depois / Anjuli Tostes, Hugo Melo Filho. Ilustração de Carlo Giambarresi. Bauru: Canal 6, 2020, p. 15-30.

MALHEIRO, Emerson. Curso de direitos humanos. São Paulo: Atlas, 2016. Livro eletrônico, paginação irregular.

MAZZUOLI, Valerio de Oliveira. Curso de Direitos Humanos. São Paulo: Editora Forense, 2020. Livro eletrônico, paginação irregular.

PECES-BARBA MARTÍNEZ, Gregorio. La Constitución y los Derechos. Tradução livre. Bogotá(Colômbia): Universidad Externado de Colombia, 2006.

PIOVESAN, Flávia. Direitos humanos e justiça internacional: um estudo comparativo dos sistemas regionais europeu, interamericano e africano. São Paulo: Saraiva, 2015. Livro eletrônico, paginação irregular.

RAMOS, André de Carvalho. Teoria geral dos direitos humanos na ordem internacional. São Paulo: Saraiva, 2013. Livro eletrônico, paginação irregular.

SEN, Amartya. Desenvolvimento como liberdade. Tradução de Laura Teixeira Motta. São Paulo: Editora Companhia do Bolso, 2010. Livro eletrônico, paginação irregular. 
TRINDADE, José Damião de Lima. História social dos direitos humanos. São Paulo: Petrópolis, 2012. Livro eletrônico, paginação irregular. 